\title{
Investigating crucial factors affecting pharmacy students' intention to work in rural area: A quantitative approach
}

\author{
Mariatul Fadilah $^{\mathrm{a}}$, Arun Kumar Tarofder ${ }^{\mathrm{b}}$, S. M. Ferdous ${ }^{\mathrm{b}}$ and Rizma Adlia Syakurah ${ }^{\mathrm{a}}$
}

${ }^{a}$ Sriwijaya University, Indonesia

${ }^{b}$ Management and Science University, Malaysia

\section{H R O N I C L E}

\section{Article history:}

Received: January 152019

Received in revised format: May

152019

Accepted: June 17, 2019

Available online:

June 17, 2019

Keywords:

Pharmacy

Job Intention

Rural

Urban

Interest

Intention to work

\begin{abstract}
A B S T R A C T
Maldistribution of skilled health workers between urban and rural area, especially pharmacist has become a global phenomenon. Not only the developing countries but also the developed country like the United States has been facing the same issue for a decades. Thus, many researchers have been trying to figure it out the reasons behind this occurrence. In their studies, most of the researchers agreed that fresh graduates from pharmacy school were willing to work in the rural area. Therefore the primary aim of this study is to identify the important factors that can affect pharmacy students' intention to work in rural area. Additionally, this study also tests the mediating effect of interest on the intention to work in the rural area of pharmacy students. A conceptual model is developed based on the two popular theories; namely theory of individual behavior and theory of interest. This model consists of three independent and one mediating and dependent variable. A quantitative approach is used to test the hypotheses. With a structured questionnaire, this study is managed to get 675 students from different pharmacy schools. Multiple regression and Sobel tests are applied to test the direct and mediating effect. Results show that two out of three had a significant direct effect on pharmacy students' intention to work in rural area. Similarly, a mediating effect also reveals the same. Based on the results, it is clear that predisposing variable is the most important for the pharmacy students' interest to work in the rural area. The finding of this study, indeed, fills the paucity of the empirical evidence regarding pharmacy students' working intention to the rural area, especially in the Indonesian context. Based on the findings, this study provides several recommendations for the government as well as pharmacy curricula developer.
\end{abstract}

\section{Introduction}

One of the utmost important components of the health care system is associated with health workers including a pharmacist. Many prior studies utterly mentioned that ensuring adequate distribution of skilled health care worker significantly improves patients' health and satisfaction. Most of the prior studies explicitly suggested that not only medical doctors, but also other professional are equally vital to provide an effective health care system (Thammatacharee et al., 2013; Lee \& Nichols, 2014; Green \& Kreuter, 1999). According to World Health Organization (WHO), "a health workforce refers to 'all people whose primary intention is to enhance health'; this includes clinical staff such as physicians, nurses, * Corresponding author.

E-mail address: mariatulfadilah@ffk.unsri.ac.id (M. Fadilah) 
dentists and pharmacists, as well as those who support or manage the system but are not directly involved with providing health services." However, disequilibrium between supply and demand of medical workers is a global phenomenon. Accessibility of an effective health care service including the availability of medicine is minimal due to the shortage of pharmacist in a rural area (Ray et al., 2015). Prior studies explicitly mentioned the lack of accessibility of the health worker in the rural area elevates the cost of health care in the rural area. In relation to maldistribution of a pharmacist, Kirschbaum et al. (2016) reported that there was a huge gap of 22,676 pharmacists in Australia. In fact, they also confirmed that $76 \%$ pharmacist worked in urban and only $12.5 \%$ work in rural area.

Indonesia is the world's largest archipelago country, consisting of wide-spread islands from Sabang to Merauke with numerous geographical variations from area to area. With the five largest islands, Indonesia is divided into two main areas; namely urban and rural (Budhathoki et al., 2017). During the last two decades, the Indonesian government has been struggling to improve their medical system across the country. As a result, Indonesian government reformed the health care policy by decentralizing this sector in 2001 (Gunawan \& Aungsuroch, 2015). The primary aim of this decentralization is to diffuse regional autonomy given to the local government. In fact, it is written to the law 32 of 2004 that the aim of this decentralization is to augment the entire health care system, subsequently elevate the community welfare (Tayyaba, 2012). In line with this, Indonesian and Japanese government developed a project called Japan International Corporate Agency (JICA) which funded for new medical university emphasis on Faculty of medicine and health science. Despite increasing the number of medical and pharmacy schools from 40 to 72 , still, it is very minimal compared with the huge demand in Indonesia. In one statistics related to physician, there will be a huge gap of 230,813 in 2025 compared with 43,162 in 2014 (BPPSDM 2011). Similar results can be found related to the pharmacist. There is a huge gap of skilled pharmacist across the Indonesia.

Additionally, Indonesia government is encountering challenges not only related to the lack of skilled health worker but also the distribution gap between rural and urban areas. There is a huge health worker distribution gap of 80:20 ratio between urban and rural area (Gunawan \& Aungsuroch, 2015). As a results government has often used new rules including compulsory service and incentives. Despite taking several initiatives, Indonesia still encounters the serious maldistribution of health workers not only in the different geographical area but also between the public and private sectors. Health professional, especially, pharmacists are highly focused in the urban area due to the private sector (Playford et al., 2017). Therefore, the aim of this study is to understand the critical factors affecting pharmacist intention to work in the rural area. Moreover, this study validates the theory of interest in line with pharmacist job behavior.

It is expected that after understanding factors related to the interest of working in rural areas, it will be possible to describe the pattern of student enrolment to the Faculty of Medicine and having the interest to work in rural areas. Eventually, it is expected that each Faculty of Medicine will be able to predict the pattern of student interest and distribution to rural areas. Distinguishing the pattern of medical students showing interest to work in rural areas for each Faculty of Medicine would eventually assist policymakers to resolve the doctor distribution disparity in Indonesia as well as further our knowledge in this subject. Moreover, this is one the very few studies that applies the theory of interest to understand the pharmacists' job behaviour. Additionally, most of the prior studies mainly were qualitative or case study in nature, however, this study provides a strong empirical foundation related to pharmacist job nature.

\section{Theoretical Framework}

\subsection{Individual Behavior}

Individual behaviour is a complicated system and differs from each other. It can be defined as an emotional response to the external or internal stimuli. Essentially, behaviour and behaviour-related issues are influenced by genetic and environmental factors (Notoatmodjo, 2011; Sridhar et al., 2014). Ashim (2010) 
mentioned that understating basic human cognition is the prerequisite to comprehending the individual behaviour. In his study, he developed an integrated human behaviour model. He explicitly articulated in his model that "Cognition is the thought process in humans that describes how the information we constantly acquire is transformed, stored and used as knowledge in future decision making". He also added that behaviour is the ultimate outcomes of this complicated cognitive process. In a similar fashion, Notoatmodjo (2014) articulated that behaviour is nothing but the reaction toward the stimulus.

Similarly, Green et al. (1980) proposed long before Ashim (2010) and still one of the popular theory in understanding individual's behaviour. Theoretically, Ashim (2010) listed seven factors that affect the individual's behaviour, including ability, gender, race, perception, attribution, attitude, and personality. On contrary, Lawrence (1980) proposed three important determinants that shape the individual's behaviour, which has been used in this study to understand the individual's job intention. These variables are: predisposing factors' enabling factors and reinforcement factors.

\subsection{Predisposing factors}

This factor is the first and most popular variables from the PRECEDE-PROCEED model developed by Lawrence Green (1980). He defined predisposing factor as factors that influence individual prior to a behaviour occurring by manipulating person's interest to act that particular behaviour (Miranda, Chamorro-Mera et al., 2017). Theoretically, he adopted this factor from Andersen and Stycos model, where they articulated that predisposing factor which changes individual's motivation through direct communication or education (Pipithirankarn, 2006). In recent studies, Huang and Du (2018) individual's knowledge, believes, self-efficacy is the name of few considered as the primary dimensions of the predisposing factors. In their study Narang (2011) mentioned that predisposing factors are difficult to change or amend thorough education (Miranda et al., 2017).

\subsection{Enabling factors}

Lawrence Green (1980) defined enabling factors as influential determinants that significantly modify individual's behaviour. Basically, Green (1995) adopted this factor from the Ronald Andersen's Behavioral Model (Pipithirankarn, 2006). In recent studies Liu et al.'s (2017) enabling factors mainly emphasis on the individual's skills, benefits of some action and so on. This factor is one of the most important factors that modifies an individual's behaviour (Bandura et al., 2014).

\subsection{Reinforcing factors}

In a similar fashion, Lawrence Green adopted this variable from Ronald Andersen's Behavioral Model and defined as the factors that change an individual's behaviour either naturally or forcefully (Huda, 2018). This factor mainly remains active in the external environment and often an individual cannot control, for example, government rules affect individuals' certain behaviour.

\subsection{Theory of Interest}

Interest is an emotional response to any allure things, activities, people or even experience. In other words, interest is a tendency to willing to participate and committed continuously (Playford et al., 2017). It can be a sign of an individual's willingness to exert certain behavioural outcome. And the outcomes can be both positive and negative (Syahmar et al., 2016). Similarly, Suharyat (2009) mentioned that interest is a combination of three components including cognition, emotion and conation. In his theory, cognition mainly is related with a sense of interest derived from knowledge and information pertaining to a specific object, person or fact, whereas emotion link with feeling gain through participation or experience (Khalil \& Halis, 2017). Lastly, conation mainly represents individual's willingness or desire to participate arise due to the other two components. Theoretically, interest has two main dimensions (Ray et al., 2015) namely desire and willingness which are not static and change time to time. Many recent studies emphasis to understanding the factors influencing interest and mentioned that personal factors, 
social factors, and external factors are three key determinants that shape the individual's interest in the workplace (Theories \& Practice, n.d.). Hence this study used interest as a mediating factor, which leads pharmacy student's intention to work in rural area.

\section{Development of the Conceptual Model}

This study proposed a conceptual model and portrait in Fig. 1. This conceptual model is mainly developed based on this two theories and empirical studies. This model consists of three independent, one mediating and dependent variables. Hypotheses related to the model are present in the next section.

This first independent factor in this conceptual model is predisposing factors. This factor is mainly related to the attribute of the individual that has a greater impact on an individual's interest. Many prior studies related to the medical doctors' intention to work in a rural area utterly mention that predisposing factors have a significant positive effect on their willingness (Borracci, 2015; Syahmar et al., 2015; Jutzi et al., 2009; Campbell, 2012; Prytherch, 2012). In this study, predisposing factors mainly measure by the pharmacy students' living experience in the village, travel hobby, societal activities during the study, and working for needy people. In their study, Borracci, (2015) identified a strong association between travel hobby and living experience of medical students with their interest in working rural area. In a similar fashion, Prytherch (2012) identified a significant positive effect of engaging social activities and interest in working in the rural area. Hence, this study proposed the following two hypothesis:

Hla: There is a significant positive direct effect on predisposing factors on the pharmacy students' intention to work in rural area.

H1b: There is a significant positive mediation of predisposing factors on pharmacy students' intention to work in rural area through arising interest.

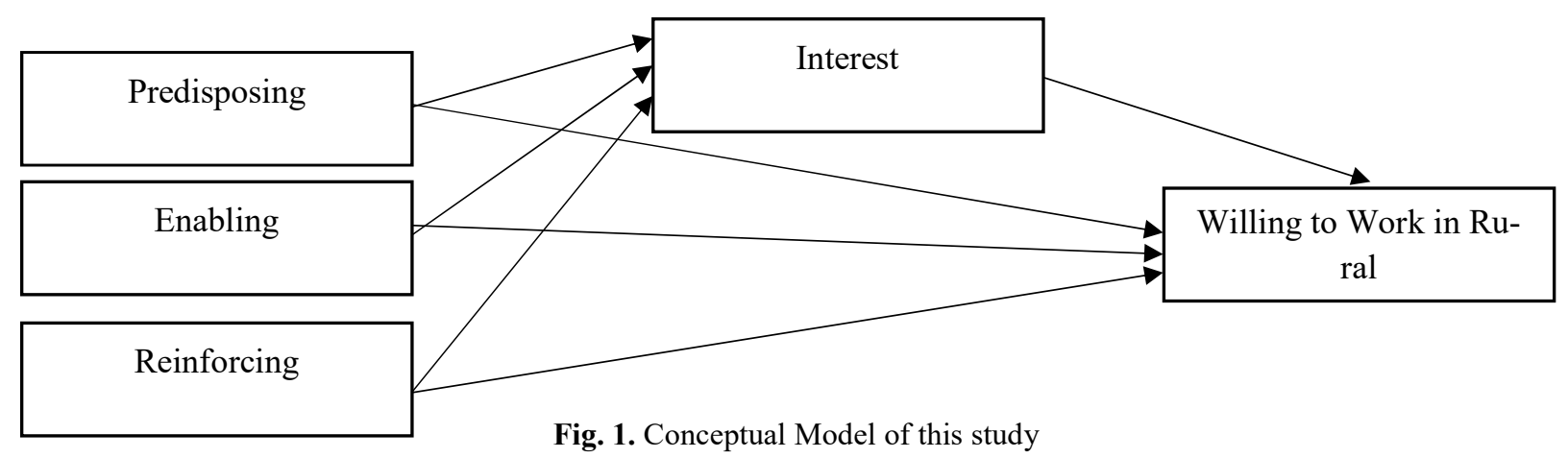

\subsection{Enabling Factors}

This is one of the most popular factor identified by almost every prior studies to understand the students' intention to work in the rural area for different subjecting including medical, pharmacy (Kirschbaum et al., 2016), entrepreneurship (Miranda et al., 2017), the name of few (Llewellyn, 1996). This factor is mainly related to supporting factors that raise students' interest in working, which eventually affect their intention. This factors mainly includes attractive incentives, carrier opportunity or growth, economic benefits and so on (Ray et al., 2015). In their study, Lehmann et al. (2008) utterly mentioned that economic benefits or incentives are the main lures for any students which arise their interest to work and eventually affect their intention to work in rural area. In a similar fashion, (Lebek et al., 2014) explicitly concluded that carrier opportunity plays an important role influencing gen $\mathrm{Y}$ to work in rural area. Hence this study propose the following hypothesis: 
H2a: There is a significant positive direct effect on enabling factors on the pharmacy students' intention to work in rural area.

$H 2 b$ : There is a significant positive mediation effect of enabling factors on pharmacy students' intention to work in rural area through arising interest.

\subsection{Reinforcing Factors}

This is the third independent factor in this study, which is mainly related to the policies developed by the government. Moreover, this factor is also related to family pressure. Basically, reinforcement factors are derived from external pressure. In their study Budhathoki et al. (2017) mentioned government regulation had a significant effect on medical doctors' intention to work in rural area. Moreover, in many countries, such as Thailand, Australia developed higher education policy, which encourages fresh pharmacy graduate to work in rural area. By implementing this policy, the government was able to encourage many young students working in the rural area (Bandura et al., 2014). Beside this, Mollahaliloglu et al. (2012) also mentioned pressure from spouse plays an important role on the individuals' intention work. However, there is no research conducted on the relationship between reinforcement factors and individuals' interest. Hence this study prosed the following hypothesis:

H3a: There is a significant positive direct effect of reinforcement factors on the pharmacy students' intention to work in rural area.

H3b: There is a significant positive mediation effect of reinforcement factors on pharmacy students' intention to work in rural area through arising interest.

\subsection{Research Approach}

A quantitative approach was applied in this study to test the hypotheses. Primary data was collected through a questionnaire survey in a face-to-face environment. This study applied a cross-sectional design to collect data. Moreover, this study applied two different types of research design namely, exploratory and hypothesis testing. An exploratory study, primarily, helps to develop the research model. On the other hand the hypothesis testing approach helps to test the hypothesis. In relation to the paradigm, this study is dealt with realism because realism deals with external reality and in this study, understanding reality is one of the key concerns.

\subsection{Questionnaire Development}

A structured questionnaire was developed to collect primary data for this study. Several important measures have been taken into consideration in developing this questionnaire suggested by Sekaran and Bouige (2016). At the initial stage of questionnaire development, this study developed an operational and conceptual definition of all the variables, which provides a guideline for the researchers in developing items for the variables. In the second stage of the instrument development, this study identified and adapted items from the prior studies, which ensure face, content and construct validity for this study. Basically, a questionnaire of this study had three sections; namely, demographic, behavioural and recommendations.

In the demographic section, age, gender, level of education and so on were asked respondent and all these questions were measured with categorical scale. The primary aim of this section was to understand the characteristics of the respondents for this study. In the second section, all the behavioural questions were included and measure with 5 points Likert scale. Total 23 items were adopted from previous studies and asked in this section to measure the five variables included in the conceptual model. Discriminant validity was tested through exploratory factor analysis and results are presented in Table 1.

Moreover, this study also applied the principles of wording and measurement suggested by Sekaran and Bougie (2016). In their book, they mentioned that research should avoid sensitive, double barrel, loaded 
and so on questions. This study strictly followed all these principles. Additionally, a pilot test was conducted with the pre-test questionnaire to ensure the internal consistency of the scale. Based on the result of the pilot test, this study finalizes the questionnaire for the final survey as the Cronbach Alpha value was more than 0.70 . Indeed, all these steps ensured an effective instrument for this study.

\subsection{Sampling strategy}

Five steps of strategy have been applied in this study to find the right sample suggested by Sekaran and Bougie (2016). At the first stage of the sampling, this study identified the appropriate population for this study, which includes final year medical students, who were pursuing an internship in different hospitals in Indonesia. A total number of 3122 intern medical students were identified from the different hospital who were about to finish their MBBS degree from both private and public university. Simple random sampling was employed to select the respondents. Initially, an invitation was sent to all of them with permission from the colleges and hospitals. Moreover, this study hired 10 native researchers to collect data from them. At the initial stage of data collection, a brief explanation was given to them regarding the research which helped respondents to response freely. With three months of effort, this study managed to get 675 responses from different hospitals. Respondents' attributes presented in Fig. 2.

\subsection{Respondents' Attributes}

In relation to respondents' attributes, results indicated that most of the respondents were male (72.44\%). This is probably due to the students' distribution in Indonesia. Based on the results, it is clear that firstyear students are reluctant to participate in the survey and most of the respondents from the third year (38.07\%), followed by final (25.92\%) and second (23.40\%). Pertaining to the source of funding, most of the respondents reported that their own family is the main source $(72.44 \%)$ of their educational funding, followed by scholarship (13.77\%). Results indicated that students from private universities were higher than public and most of the respondents spend their childhood in the city $(52.75 \%)$.

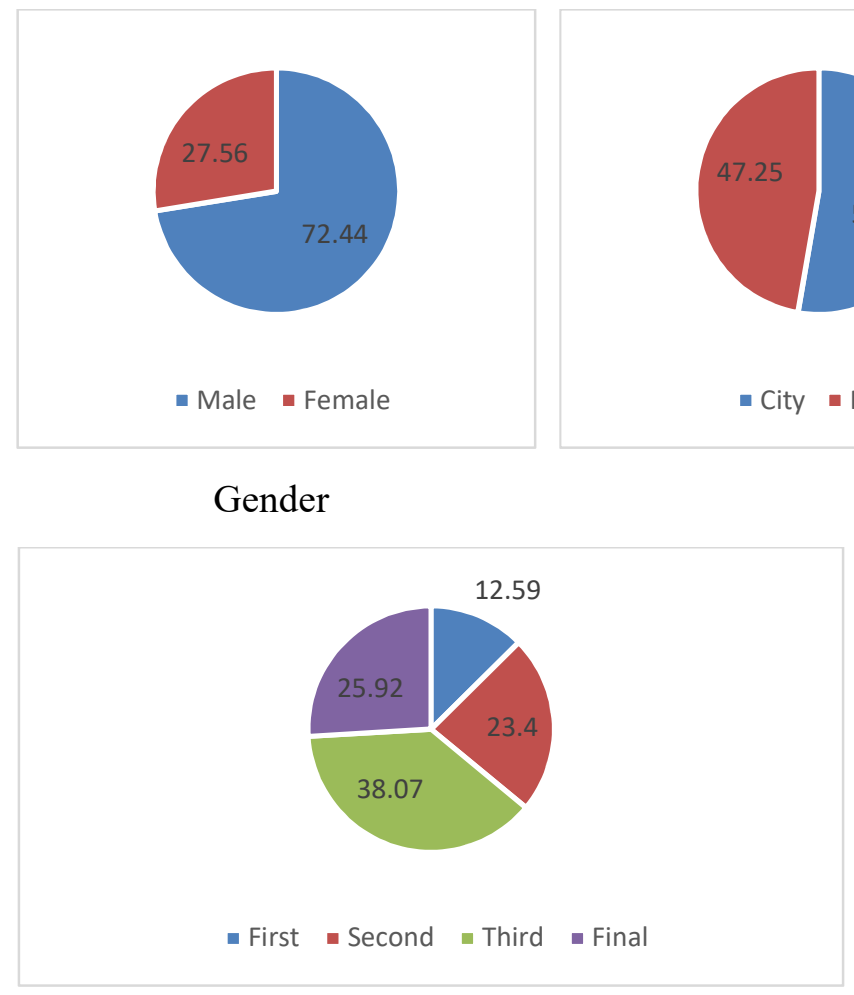

Year of education

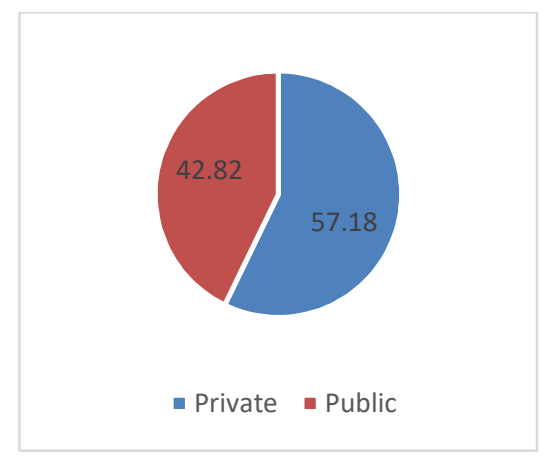

University type

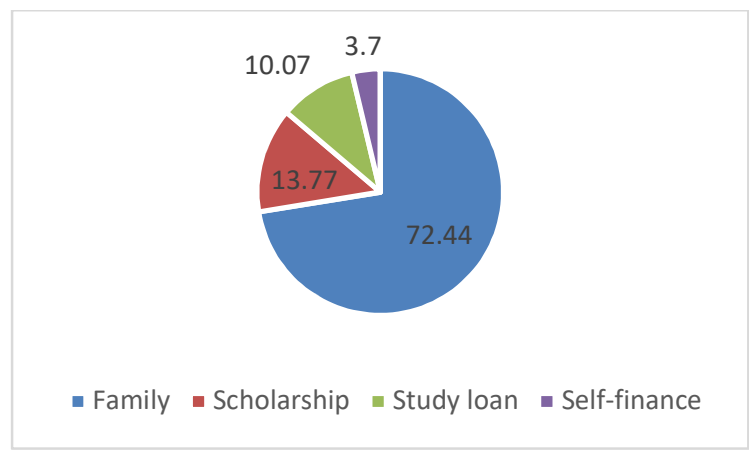

Source of funding

Fig. 2. Personal characteristics of the participants 


\subsection{Hypothesis testing}

This study followed three steps in testing the hypotheses proposed. In the first step, this study applied Exploratory Factor Analysis (EFA) to uncover the underlying structure of the relatively large set of variables, followed by the direct effect of independent with dependent and mediating effect. EFA results presented in Table 1 with Cronbach alpha value. Based on the alpha value it is clear that data for this study was reliable as the minimum alpha value is 0.787 . Moreover, KMO value assured that the sample is adequate for this study as the value is 0.864 . In relation to a number of variables, initial eigenvalues confirmed that there are total five variables having initial eigenvalues more than 1 , which had been considered for the multivariate analysis and also fir with the proposed model. These five variables explained 78.73 per cent of total variance. With the five items and minimum factor loading value of .899, predisposition became the highest and the first variable that explained 22.03 per cent variance of intention to work in rural area. Secondly, four items with minimum loading of .939, enabling factor explained 16.14 per cent variance of the dependent variable. Last but not least, the initial eigenvalue of 3.413 and minimum loading value of .838 , reinforcement variable was built. Due to the satisfactory value in every criterion of EFA, this study brought forward all these independent variables to test the proposed hypothesis.

\section{Table 1}

Results of Reliability and Factor Analysis

\begin{tabular}{|c|c|c|c|c|c|}
\hline $\begin{array}{l}\text { Kaiser-Meyer-Olkin Measure of Sampling Ade- } \\
\text { quacy. }\end{array}$ & & & 0.864 & & \\
\hline Bartlett's Test of Sphericity & & & 0.000 & & \\
\hline Factor Items & $\begin{array}{l}\text { Factor } \\
\text { Loading }\end{array}$ & $\begin{array}{l}\text { Composite } \\
\text { Mean }\end{array}$ & $\begin{array}{c}\text { Cronbach's } \\
\text { Alpha }\end{array}$ & $\begin{array}{l}\text { Initial Ei- } \\
\text { genvalues }\end{array}$ & $\begin{array}{c}\text { \% of var- } \\
\text { iance }\end{array}$ \\
\hline Predisposing & & \multirow{6}{*}{3.751} & \multirow{6}{*}{.869} & \multirow{6}{*}{5.120} & \multirow{6}{*}{22.031} \\
\hline Experience in staying rural places. & .935 & & & & \\
\hline Travelling hobby & .921 & & & & \\
\hline Family background from rural area & .913 & & & & \\
\hline Lifestyle in school & .908 & & & & \\
\hline Social motive & .899 & & & & \\
\hline \multicolumn{2}{|l|}{ Enabling } & \multirow{5}{*}{3.812} & \multirow{5}{*}{.825} & \multirow{5}{*}{4.013} & \multirow{5}{*}{16.124} \\
\hline Infrastructure in rural area & .981 & & & & \\
\hline Earning facility in rural area & .976 & & & & \\
\hline Carrier Opportunity & .952 & & & & \\
\hline Academic Opportunity & .939 & & & & \\
\hline \multicolumn{2}{|l|}{ Reinforcing } & \multirow{6}{*}{3.851} & \multirow{6}{*}{.787} & \multirow{6}{*}{3.413} & \multirow{6}{*}{14.176} \\
\hline Government regulations & .897 & & & & \\
\hline Collage policy & .881 & & & & \\
\hline Job replacement policy & .869 & & & & \\
\hline Family pressure & .852 & & & & \\
\hline Medical association's regulation & .838 & & & & \\
\hline \multicolumn{6}{|l|}{ Interest } \\
\hline Want to explore different places with my job & .962 & \multirow{4}{*}{3.531} & \multirow{4}{*}{.852} & \multirow{4}{*}{3.201} & \multirow{4}{*}{13.741} \\
\hline $\begin{array}{l}\text { Want to experience intrinsic pride by serving } \\
\text { country }\end{array}$ & .955 & & & & \\
\hline Want to be close with society that need help & .943 & & & & \\
\hline Want to experience spatiality & .937 & & & & \\
\hline \multicolumn{2}{|l|}{ Intention to Work } & & & & \\
\hline I like to serve the community & .946 & 3.551 & .876 & 2.754 & 12.658 \\
\hline
\end{tabular}

\subsection{Direct Effect of Independent variables on Customer Satisfaction and Repurchase Intention}

This study applied multiple regression to test the direct effect of the independent variable on dependent and results presents in Table 2 . In relation with the model fit, ANOVA results confirmed a perfect fit for both interest and intention to work. These three variables explained the variance of interest and intention 
work by $69.5 \%$ and $63.3 \%$ respectively. Regression results depict that two out three variables are important for young pharmacy students' intention to work in rural area. More specifically, results confirmed that predisposing is the utmost important factor influencing their working intention to a rural area and it explained the variance of intention to work by $54 \%$. Similarly, enabling factors also play an important role to the pharmacy students' working intention to the rural area and explained $35.5 \%$ variance. Additionally, results indicate that reinforcing factors do not have any significant effect on the pharmacist intention to work in rural area.

Table 2

Regression Results

\begin{tabular}{cccccc}
\hline Predictor Variables & Beta & t-value & Sig value & Tolerance & VIF \\
\hline Predisposing & 0.540 & 9.809 & 0.000 & .690 & 1.450 \\
Enabling & 0.353 & 6.426 & 0.000 & .694 & 1.122 \\
Reinforcing & 0.034 & .708 & 0.480 & .891 & 1.450 \\
\hline Dependent Variable: Intention to $\boldsymbol{W o r k} ; \boldsymbol{A d j u s t e d ~} \boldsymbol{R}^{\mathbf{2}} \mathbf{= . 6 3 3 ;} \boldsymbol{F}$ value $=\mathbf{1 0 2 . 0 0 3 ;}$ Sig value $=.000$ & .891 & 1.122 \\
\hline Predisposing & 0.589 & 13.340 & 0.000 & .690 & 1.450 \\
Enabling & 0.321 & 6.393 & 0.000 & .694 & 1.442 \\
\hline Reinforcing & 0.165 & 3.303 & 0.001 & & \\
\hline
\end{tabular}

Dependent Variable: Interest; $R^{2}=.695 ;$ F value $=134.450 ;$ Sig value $=.000$

On the other hand, all three variables have maintained significant influences on the interest. Again, predisposing variables play the most important role in developing interest among pharmacy students and explained $58.9 \%$ of the variance. In fact, almost every prior studies agreed that the predisposing factor is an important influencing factor for arousing interest in working rural area (Tayyaba, 2012). In relation to this, Syahmar et al., (2015) utterly mentioned that involved in community-based activities in student life influence and encourage students to work in rural area. Similarly, Campbell, (2012) stated that having experience of living in village influence pharmacist willing to work in rural area. Results of this study also reconfirmed the importance of this variable on the intention to work in rural area. Secondly, Nallala et al. (2015) suggested in their study that carrier opportunity in the rural area plays an important role in encouraging pharmacist to work in a rural area. In a similar fashion, Silvestri et al. (2014) identified that the economic condition of the students' family had a significant role in their working behaviour. In line with all these prior studies, results of this study reconfirmed that enabling factors to have a significant effect on the interest of pharmacy students' working behaviour in the rural area. In fact, it is the second most important factor and explained $32.1 \%$ variance of the interest in working in the rural area. Reinforcing factor has a minimal but significant effect in arousing interest in working rural area. Results indicated that $16.5 \%$ variance of interest explained by this factor. In similar fashion, many prior studies concluded that reinforcing factors have minimal effect or no effect on arousing interest. Though students can avoid the rule and it does play a very minimal role in arousing interest in working rural area (Mollahaliloglu et al., 2012; Araujo \& Maeda, 2013).

\subsection{Mediating effect of Interest on Intention to Work in the Rural area}

To test the mediating effect, this study applied three steps of the Sobel test developed by Baron and Kenny Approach (1986). Later it became a very popular method among behavioural scientist. Baron and Kenny suggested the following three steps

1) Firstly, apply regression analysis to measure the significant effect of independent variables on the dependent variables. However, mediation analysis can be stopped, if there is no sign of a significant effect of independent variable on the dependent.

2) Second step mainly emphasis on measuring regression between independent and mediator variables. 
3) And in the final step, measure the significant effect of independent and dependent variable together on the dependent variable.

Results of all these three steps are presented in Table 3. Afterwards, this study calculates the path coefficient to find the mediating effect in the following manner.

$\mathrm{A}=$ Standardized Coefficient of the independent variable on the dependent,

$\mathrm{B}=$ Standardized Coefficient of independent variables on the mediator,

$\mathrm{C}=$ Standardized Coefficient of independent and mediator on the dependent.

As a rule of thumb for mediating effect, if $\mathrm{AB}(\mathrm{A} \times \mathrm{B})$ values are more than $\mathrm{C}$, then there is the significant mediating effect of mediator on the dependent. Not only this, Sobel (1982) also suggested a method to estimate the significance of the mediation effect and later become popular as well. In his study, he proposed the following formula to calculate the significance of the mediation effect:

$$
\begin{aligned}
& S E_{a b} \approx \sqrt{b^{2} s_{a}^{2}+a^{2} s_{b}^{2}}, \\
& z=a b / S E_{a b}
\end{aligned}
$$

where

a (Unstandardized Coefficient of independent variables Predicting moderator)

b (Unstandardized Coefficient of moderator Predicting dependent)

$\mathrm{S}_{\mathrm{a}}$ (Standard error for a regression coefficient)

$\mathrm{S}_{\mathrm{b}}$ (Standard error for $\mathrm{b}$ regression coefficient)

Table 3

\begin{tabular}{|c|c|c|c|c|}
\hline Hypothesis & Step 1 & Step 2 & Step 3 & $\begin{array}{l}\text { Sobel Test of } \\
\text { Significance }\end{array}$ \\
\hline $\mathrm{H} 1 \mathrm{~b}$ & $\begin{array}{c}\text { Predisposing } \rightarrow \text { Inten- } \\
\text { tion to work } \\
\beta \text { Predisposing }=-.540, \\
p<0.0005\end{array}$ & $\begin{array}{c}\text { Predisposing } \rightarrow \text { Inter- } \\
\text { est } \\
\beta \text { Predisposing }=-.589, \\
p<0.0005\end{array}$ & $\begin{array}{c}\text { Predisposing }+ \text { Interest } \rightarrow \\
\text { Intention to Work } \\
\beta \text { Predisposing }=-.219-p=0.000 \\
\beta_{\text {Interest }}=.378, p<0.000\end{array}$ & 4.58 \\
\hline $\mathrm{H} 2 \mathrm{~b}$ & $\begin{array}{c}\text { Enabling } \rightarrow \text { Intention } \\
\text { to work } \\
\beta \text { Enabling }=.353, \\
p<0.0005\end{array}$ & $\begin{array}{c}\text { Enabling } \rightarrow \text { Interest } \\
\beta_{\text {Enabling }}=0.321 \\
p<0.0005\end{array}$ & $\begin{array}{c}\text { Enabling }+ \text { Interest } \rightarrow \text { Inten- } \\
\text { tion to Work } \\
\beta_{\text {Enabling }}=.101, p=0.419 \\
\beta_{\text {Interest }}=.439, p<0.0005\end{array}$ & 3.51 \\
\hline $\mathrm{H} 3 \mathrm{~b}$ & $\begin{array}{c}\text { Reinforcing } \rightarrow \text { Inten- } \\
\text { tion to work } \\
\beta \text { Reinforcing }=.034 \\
p<0.0005 \\
\end{array}$ & $\begin{array}{c}\text { Reinforcing } \rightarrow \text { Inter- } \\
\text { est } \\
\beta_{\text {Reinforcing }}=.165 \\
p<0.0005 \\
\end{array}$ & $\begin{array}{c}\text { Reinforcing }+ \text { Interest } \rightarrow \text { In- } \\
\text { tention to Work } \\
\beta_{\text {Reinforcing }}=.551, p=0.02 \\
\beta_{\text {Interest }}=.322, p<0.0005\end{array}$ & 1.21 \\
\hline
\end{tabular}

Results of the Mediating Effect

Results of the Sobel test presented in Table 3. Moreover, he concluded that in order to have significant mediating effect mediator, $Z$ value must be more than 1.96 at 95 per cent confidence interval. Hence, this study concluded the mediating effect of interest on dependent based on both 'AB' values and $Z$ values. In relation with predisposing, results of Table 3 indicated that the $\mathrm{AB}$ value was 0.318 (.540×.589), which was more than $C$ value (0.219). Moreover, the $Z$ value was more than 1.96 , which ensures the mediating effect of interest on pharmacy students' intention to work in the rural area by predisposing variables. Similarly, 'AB' value for enabling factors was 0.113 and the 'C' value was 0.101 . Not only this, but results also depicted $Z$ value is more than 1.96 . Hence it is clear that there is also a significant mediating effect of enabling factors on pharmacy students' intention to work in the rural area by arousing interest. On the other hand, results clearly show that there is no significant mediating effect of reinforcing variables on the intention to work as its $A B$ value is less than the $C$ value and also $Z$ value is less than 1.96 . 


\section{Contributions and Practical Implication}

This current research has various contributions in both theoretical and practical domain. Moreover, this is one of the very few studies that has been conducted in Indonesia emphasizing on the pharmacy students' intention to work in rural area. Most of the available prior studies were related to medical students or doctors. Hence, this current study fulfills the significant lacuna in the area of the pharmacists' job intention. Firstly, the result of this current study confirmed that the predisposing factor was the most influential for the pharmacist arousing intention to work in rural area. A similar conclusion was made by Syahmar et al. (2015). They mentioned that the lifestyle of the students strongly influence the young pharmacist. Similarly, Mollahaliloglu et al. (2012) utterly suggested that attractive social motives always encourage young pharmacist to work in a rural area. Hence, this study reconfirmed their findings in the different context and in a different country. Additionally, this study has shown that predisposing factors not only influences directly but also has a mediating effect through arousing interest. This can be an additional contribution to the theory of interest. Very few prior studies in the area applied this theory and extended by adding the variable called interest. According to Boracci et al. (2015), identifying the influential factors affecting the interest may give the right direction for the education and human resource ministry developing the right set of policy. The current study has shown a strong relationship between predisposing factors and interest, which eventually affects the willingness of working in the rural area.

Secondly, enabling factors, such as carrier opportunity, incentives, have strong direct influences on the intention of working in the rural area. Without a doubt, many prior studies utterly mentioned that enabling factors facilitate young pharmacist economically. Attractive package, well-developed infrastructure have strong influences on the young pharmacist intention to work in rural area. Pertaining to enabling factors, Khalil and Halis (2017) suggested that in order to encourage medical students to work in rural area, hospitals and government must provide allure package, including attractive incentives, better carrier development, and modern infrastructure. Similarly, Playford et al. (2017) utterly mentioned in their study that carrier advancement and opportunity for further education were the two most attractive factors for the medical students to work in the rural area. Results of this study also reconfirmed the similar results for the pharmacist. Additionally, this study also confirmed the mediating effect of enabling factors on intention to work in rural area through arousing interest. In other words, enabling factors has a strong effect on arousing interest among young pharmacy students and encourage them to work in the village. Indeed, this study is one of the very few empirical studies that confirm the theory of interest in relationship with the mediating effect of interest in the context of the pharmaceutical industry.

Finally, this study identified interesting results regarding reinforcement variables. Specifically, results have shown that there was neither direct nor mediating effect of reinforcement on the intention to work as well as interest. Though many prior studies strongly suggested that by reinforcing, government could bring pharmacist in the rural side. However, there are many drawbacks of this reinforcement policies. This study confirmed that this variable is not able to encourage pharmacy students to work in the rural side. This result can be an eye-opening findings for the pharmaceutical industry in Indonesia as well as for the Indonesian government.

Based on the results, there are several practical implications of this study. Firstly, this study strongly recommended an important change in the pharmacy curriculum. In other words, the university must develop community-based curriculum system in which student learn their lesson practically by improving the community welfare. Not only university but also the education ministry should take this recommendation seriously and encourage every university as well. Secondly, government and university must provide an educational opportunity for rural students, as this study confirmed that students who have experience living in the village are more likely to work in rural area. Hence, it would be better if the government encourage rural student studying pharmacy. 
Similarly, this study strongly recommends government and university authorities that they enrol students into medical schools on the basis of their positive inclinations towards rural service to ensure an equitable and proportionate distribution of physicians in both rural and urban environments. In fact, the government should develop provision for the admission into the pharmacy schools for students from or in the vicinity of rural communities or pharmacy schools located in districts should admit students that live close to the institution. Besides these policies, it is strongly recommended based on the results that the government offer an attractive incentives plan, including carrier growth, benefits to encourage young pharmacist to work in the rural area. Last but not least, government and universities must build an advance pharmaceutical lab in the rural area which will definitely encourage pharmacist to work in the rural area.

\section{Limitations and Further study}

Despite minimizing many limitations by adhering scientific research techniques, some limitations are inevitable. Firstly, random error is a major concern for the empirical data, hence the results related to this data likely differ with other data. Though this study minimizes this error by adopting scales from prior studies, however, development of scale, validation are a continuous process and requires longitudinal data set. Hence this study can be extended by designing a longitudinal research. Secondly, this study only considers three variables and this variable explained nearly 65 per cent of the variance. Thus, this research can be advanced by adding more variables. Last but not least, the result of the current study can be generalized to some extent but to understand the reality this study needs more sample from a different culture and must compare with other industry as well.

In spite of having very few limitations, this study provides a well understanding of the Indonesian pharmacy student behaviour related to work in a rural area. Indeed, this study is one of the very few empirical research that provides in-depth knowledge on how to encourage young pharmacist to work with the needy community, which eventually brings the community wellbeing.

\section{References}

Araujo, E., \& Maeda, A. (2013). How to recruit and retain health workers in rural and remote areas in developing countries: a guidance note.

Bandura, R. P., Johnson, R., \& Lyons, P. R. (2014). Voluntary helpful organizational behaviour: Recognition of individual attributes. European Journal of Training and Development, 38(7), 610 627.

BPPSDM. (2011). Human Resources for Health Development Plan. Jakarta: Badan Pengembangan dan Perencanaan Sumber Daya Manusia, Board of Human Resources for Health Empowerment and Development.

Budhathoki, S. S., Zwanikken, P. A. C., Pokharel, P. K., \& Scherpbier, A. J. (2017). Factors influencing medical students' motivation to practise in rural areas in low-income and middle-income countries: A systematic review. BMJ Open, 7(2), 1-9.

Green, L. W., Kreuter, M. W., Deeds, S. G., Partridge, K. B., \& Bartlett, E. (1980). Health education planning: a diagnostic approach.

Green, L. W., \& Kreuter, M. W. (1999). Health Promotion Planning: An Educational and Ecological Approach. $3^{\text {rd }}$ edition. Mountain View, CA: Mayfield.

Gunawan, J., \& Aungsuroch, Y. (2015). Indonesia health care system and Asean economic community. International Journal of Research in Medical Sciences, 3(7), 1571-1577.

Huang, Z., \& Du, X. (2018). Farmers' attitudes toward land titling and its potential effects on rural development in China. China Agricultural Economic Review, 10(3), 425-442.

Huda, M. (2019). Empowering application strategy in the technology adoption: insights from professional and ethical engagement. Journal of Science and Technology Policy Management, 10(1), 172192.

Khalil, D., \& Halis, M. (2017). Challenges facing the quality of education in the Libyan higher technical colleges. Imperial Journal of Interdisciplinary Research (IJIR), 3(10), 112-118.

Kirschbaum, M., Khalil, H., Talyor, S., \& Page, A. T. (2016). Pharmacy students' rural career intentions: 
Perspectives on rural background and placements. Currents in Pharmacy Teaching and Learning, $8(5), 615-621$.

Lebek, B., Uffen, J., Neumann, M., Hohler, B., \& Breitner, M. H. (2014). Information security awareness and behavior: A theory-based literature review. Management Research Review, 37(12), 1049-1092.

Lee, D. M., \& Nichols, T. (2014). Physician recruitment and retention in rural and underserved areas. International Journal of Health Care Quality Assurance, 27(7), 642-652.

Liu, J., Li, X., \& Guo, Y. (2017). Periodicity analysis and a model structure for consumer behavior on hotel online search interest in the US. International Journal of Contemporary Hospitality Management, 29(5), 1486-1500.

Llewellyn, S. (1996). Theories for theorists or theories for practice? Liberating academic accounting research? Accounting, Auditing \& Accountability Journal, 9(4), 112-118.

Miranda, F. J., Chamorro-Mera, A., Rubio, S., \& Pérez-Mayo, J. (2017). Academic entrepreneurial intention: the role of gender. International Journal of Gender and Entrepreneurship, 9(1), 66-86.

Mollahaliloglu, S., Aydogan, Ü., Kosdak, M., Öncül, H. G., \& Dilmen, U. (2012). Physician scarcity in underdeveloped areas of Turkey: what do new graduate physicians think? Rural \& Remote Health, 12(4).

Thammatacharee, N., Suphanchaimat, R., Wisaijohn, T., Limwattananon, S., \& Putthasri, W. (2013). Attitudes toward working in rural areas of Thai medical, dental and pharmacy new graduates in 2012: a cross-sectional survey. Human resources for health, 11(1), 53.

Nallala, S., Swain, S., Das, S., Kasam, S. K., \& Pati, S. (2015). Why medical students do not like to join rural health service? An exploratory study in India. Journal of family \& community medicine, 22(2), 111.

Narang, R. (2011). Determining quality of public health care services in rural India. Clinical Governance, 16(1), 35-49.

Pipithirankarn, M. (2006). Predisposing, Enabling and Reinforcing Factors Influence Intention To Buy Green Product, (Peattie 2001).

Playford, D., Ngo, H., Gupta, S., \& Puddey, I. B. (2017). Opting for rural practice: The influence of medical student origin, intention and immersion experience. Medical Journal of Australia, 207(4), $154-158$.

Ray, R. A., Young, L., \& Lindsay, D. B. (2015). The influences of background on beginning medical students' perceptions of rural medical practice. BMC Medical Education, 15(1), 1-9.

Sekaran, U., \& Bougie, R. (2016). Research methods for business: a skill-building approach (7th ed.). Haddington: John Wiley \& Sons

Silvestri, D. M., Blevins, M., Afzal, A. R., Andrews, B., Derbew, M., Kaur, S., ... \& Vermund, S. (2014). Medical and nursing students' intentions to work abroad or in rural areas: a cross-sectional survey in Asia and Africa. Bulletin of the World Health Organization, 92, 750-759.

Sridhar, C., Radhakumary, P., \& Applanaidu, S. (2014). Attitude of Postgraduate medical student's towards rural health service in Andhra Pradesh. IOSR Journal of Dental and Medical Sciences (IOSRJDMS), 13(9), 48-51.

Syahmar, I., Putera, I., Istatik, Y., Furqon, M. A., \& Findyartini, A. (2015). Indonesian medical students' preferences associated with the intention toward rural practice. Rural \& Remote Health, 15(4).

Tayyaba, S. (2012). Rural-urban gaps in academic achievement, schooling conditions, student, and teachers' characteristics in Pakistan. International Journal of Educational Management, 26(1), 6-26.

Theories, T., \& Practice, I. (n.d.). Individual behavior in organization Integrated human behavior model. Race.

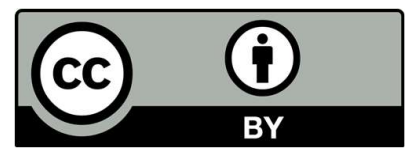

(C) 2019 by the authors; licensee Growing Science, Canada. This is an open access article distributed under the terms and conditions of the Creative Commons Attribution (CCBY) license (http://creativecommons.org/licenses/by/4.0/). 